\title{
Dynamic study of possible host stars for extrasolar planetary systems
}

\author{
N. A. Shakht, L. G. Romanenko, D. L. Gorshanov and \\ O. O. Vasilkova \\ Central (Pulkovo) Observatory RAS, \\ St- Petersburg 196140, Russia \\ email: shakht@gao.spb.ru
}

\begin{abstract}
We present the stellar systems which consist of double and multiple stars with distances $3.5 \div 25$ pc from the Sun, belonging to spectral classes F, G, K, M, having masses from 0.3 to 1.5 solar mass and can, in principle, possess planetary systems. On the basis of observations with Pulkovo $65 \mathrm{~cm}$ refractor the relative positions of double stars, the parameters of motion, the orbits and also the ephemeris for the nearest epochs have been computed.
\end{abstract}

Keywords. stars: binaries, stars: planetary systems, habitable zones

\section{Introduction}

The astrometric positional observations of single, double and multiple stars, which are located near the Sun, are carrying out in Pulkovo observatory many years. Observations are made by means of 26 -inch refractor $(\mathrm{D}=65 \mathrm{~cm} ; \mathrm{F}=10413 \mathrm{~mm})$ since 1956 . We have long-term series to $40 \div 50$ years of photographic observations with yearly error about 10 mas. The telescope functions in an automatic mode. Since 2007 year the CCD camera is used. The results of our observations of about 300 stars are collected in the Catalog of Relative Positions of Double Stars (Kiselev et al. 2014). Owing to the physical properties (a spectral class, masses, the distance to the Sun and the duration of positional observations, which allow to obtain precise parameters of movement) these stars could become objects of observations for programs exoplanets searches. It is known, that some projects are aimed at searches of planets by means of astrometric methods. These programs include the research of stars of F, G, K and M spectral classes (see, for instance, CAPS program by Boss et al. 2014 and also future project NEAT with expected microseconds precision by Malbet et al. 2014).

\section{Results of observations}

We investigate wide double stars with separation $\geqslant 4$ " and with $m<13$ mag. For computing orbits we use Apparent Motion Parameters method, see the description in Kiselev \& Romanenko (1996) and Kiselev et al. (2014). This method allows to calculate an orbit and dynamical mass of a double star on the basis of observations of a short arc if the parallax and the relative radial velocity are known. The orbits for about 50 pairs have been determined. We have the close pairs with semi-axis major $a$ from 33 to 200 AU and periods $P<2000$ years and more wide pairs with periods up to several tens of thousands of years. In the table 1 we give a short list of stars having Pulkovo orbits, their ADS and WDS numbers and spectral classes for two components. In the table 2 we give the new orbits of three stars, the distance of a star from the Sun - D and the minimum 


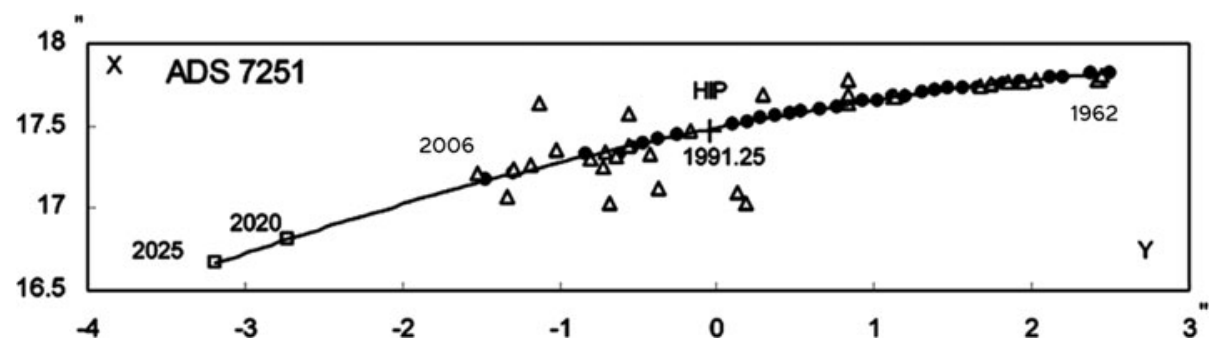

Figure 1. ADS 7251, the solid circles - Pulkovo observations in 1962-2006, the triangles - the positions from WDS catalog, the cross - Hipparcos 1991.25 and the squares - the ephemeris for 2020 and 2025 years. $\mathrm{X}=\rho \sin \theta, \mathrm{Y}=\rho \cos \theta$.

Table 1. List of the selected stars.

\begin{tabular}{|c|c|c|c|c|c|c|c|c|c|c|c|c|c|c|}
\hline ADS & WDS & $\mathrm{Sp}$ & ADS & WDS & $\mathrm{Sp}$ & ADS & WDS & $\mathrm{Sp}$ & ADS & WDS & $\mathrm{Sp}$ & IDS & WD & $\mathrm{Sp}$ \\
\hline 48 & $\mid \begin{array}{l}00 \\
+4\end{array}$ & $\begin{array}{l}\mathrm{K} 6 \mathrm{~V} \\
\mathrm{M} 0 \mathrm{~V}\end{array}$ & 8002 & $\begin{array}{l}6 \\
7\end{array}$ & $\begin{array}{c}\text { K0 } \\
-\end{array}$ & & & $\mid \begin{array}{l}\text { M1V } \\
\text { M3V }\end{array}$ & & & $\begin{array}{l}\text { K0V } \\
\text { K0V }\end{array}$ & & & $\begin{array}{l}\text { M4 } \\
\text { M4 }\end{array}$ \\
\hline 127 & $\begin{array}{l}0 \\
+\end{array}$ & $\mid \begin{array}{l}\text { M2 } \\
\text { M2 }\end{array}$ & 725 & & $\mid \begin{array}{l}\mathrm{M} 0 \mathrm{~V} \\
\mathrm{M} 0 \mathrm{~V}\end{array}$ & 9 & & $\begin{array}{l}\mathrm{K} 4 \mathrm{~V} \\
\mathrm{~K} 6 \mathrm{~V}\end{array}$ & & & $\begin{array}{l}\text { K4V } \\
\text { M0 }\end{array}$ & & & $\begin{array}{l}\text { G5V } \\
\text { G5V }\end{array}$ \\
\hline 2757 & $\left|\begin{array}{c}03470 \\
+4126\end{array}\right|$ & $\begin{array}{l}\mathrm{K} 1 \mathrm{~V} \\
\mathrm{~K} 2 \mathrm{~V}\end{array}$ & 8100 & & $\begin{array}{l}\text { K5 } \\
\text { M0 }\end{array}$ & 9 & & $\mathrm{M}$ & 86 & & $\begin{array}{l}\text { K8V } \\
\text { K8V }\end{array}$ & $\left|\begin{array}{c}12815 \\
16 \mathrm{Cyg}\end{array}\right|$ & & $\begin{array}{l}\mathrm{G} 2 \mathrm{~V} \\
\mathrm{G} 2 \mathrm{~V}\end{array}$ \\
\hline 5983 & $\left|\begin{array}{c}07202 \\
+2159\end{array}\right|$ & $\begin{array}{l}\text { F0IV } \\
\text { K6V }\end{array}$ & 8250 & $\left|\begin{array}{c}11387 \\
+4507\end{array}\right|$ & G0V & 9696 & $\begin{array}{l}15292 \\
+8027\end{array}$ & $\begin{array}{l}\text { K0V } \\
\text { K0V }\end{array}$ & 10759 & $\begin{array}{l}17419 \\
+7209\end{array}$ & $\begin{array}{l}\text { F5IV } \\
\text { F } 8 \mathrm{~V}\end{array}$ & $\left|\begin{array}{c}14636 \\
61 \mathrm{Cyg}\end{array}\right|$ & & $\begin{array}{l}\mathrm{K} 5 \mathrm{~V} \\
\mathrm{~K} 7 \mathrm{~V}\end{array}$ \\
\hline
\end{tabular}

Table 2. Orbits of binary stars and astrometric signal due to possible planets.

\begin{tabular}{|c|c|c|c|c|c|c|c|c|c|c|c|c|}
\hline ADS & & $a, a u \mid$ & $P, y r$ & $e$ & $i^{\diamond}$ & $\omega^{\diamond} \mid$ & $\Omega^{\diamond} \mid$ & $T_{p}, y r$ & $D, p c$ & $a_{p}$, au $\mid$ & $A_{\oplus}, \mu$ as $\mid$ & $A_{J u p}, \operatorname{mas} \mid$ \\
\hline 7251 & $\begin{array}{l}\mathrm{A} \\
\mathrm{B}\end{array} \mid$ & 136.9 & 1528.0 & 0.08 & 141.0 & 210.4 & 216.6 & 1882.8 & 6.1 & $\begin{array}{l}0.25 \\
0.24\end{array}$ & $\begin{array}{l}0.20 \\
0.20\end{array}$ & $\begin{array}{l}0.06 \\
0.06\end{array}$ \\
\hline 11632 & $\begin{array}{l}\mathrm{A} \\
\mathrm{B}\end{array}$ & 93.4 & 1094.1 & 0.42 & 106.7 & 319.3 & 145.1 & 1835.2 & 3.5 & $\begin{array}{l}0.22 \\
0.14\end{array} \mid$ & $\begin{array}{l}0.52 \\
0.36\end{array} \mid$ & $\begin{array}{l}0.16 \\
0.11\end{array}$ \\
\hline 14636 & $\begin{array}{l}\mathrm{A} \\
\mathrm{B}\end{array}$ & 81.8 & 674.3 & 0.50 & 132.5 & 156.3 & 177.1 & 1728.5 & 3.5 & $\begin{array}{l}0.35 \\
0.26\end{array}$ & $\begin{array}{l}0.44 \\
0.39\end{array}$ & $\begin{array}{l}0.14 \\
0.12\end{array}$ \\
\hline
\end{tabular}

Note: $a_{p}$ is a semi-major axis of a planet's orbit, which we proposed equal to the inner edge of habitable zone. $\mathrm{HZ}$ was computed according to Selsis et al. 2007.

of astrometric signal from planets located near to the inner edge of HZ with the Earth's $\left(A_{\oplus}\right)$ and Jupiter's $\left(A_{J u p}\right)$ masses.

We hope that our astrometric observations can be useful for comprehensive study of stars with possible planetary systems.

\section{References}

Boss, A. P., Weinberger, A. G., Anglada-Escudé, G.,Thompson, I. B., \& Brahm, R. 2014, Formation, Detection and Characterization of Extrasolar Habitable Planets Proc. IAU Symp. No 293 , 2012, ed. N. Haghighipoor, p.183

Kiselev, A. A., Kiyaeva, O. V., Izmailov, I. S., Romanenko, L. G., Kalinichenko, O. A., Vasilkova, O. O., Vasil'eva, T. A., Shakht, N. A., Gorshanov, D. L., \& Roschina, E. A. 2014, Astron.Rep. 58, 78

Kiselev, A. A. \& Romanenko, L. G.1996, Astron.Rep. 40, 795

Malbet, F.,Crouzier, A., Renaud, G. et al. 2014, Formation, Detection and Characterization of Extrasolar Habitable Planets Proc. IAU Symp. No 293 , 2012, N. Haghighipoor ed., p.448

Selsis, F., Kasting, J. F., Levrard, B. et al. 2007, A\&A 476, 1373 